\title{
Erratum to: Climate variability and change in mountain environments: some implications for water resources and water quality in the Sierra Nevada (USA)
}

\author{
Mariza Costa-Cabral • Robert Coats • John Reuter • \\ John Riverson • Goloka Sahoo • Geoffrey Schladow • \\ Brent Wolfe • Sujoy B. Roy $\bullet$ Limin Chen
}

Published online: 30 November 2012

(C) Springer Science+Business Media Dordrecht 2012

\section{Erratum to: Climatic Change (2012) \\ DOI 10.1007/s10584-012-0630-2}

Unfortunately there is a mistake in the labels of the bottom 2 graphs in Fig. 2. They should read "2040-2069 (B1)" and "2070-2099 (B1)" respectively. The corrected figure is displayed below.

The online version of the original article can be found at http://dx.doi.org/10.1007/s10584-012-0630-2.

M. Costa-Cabral $(\square)$

Hydrology Futures, LLC, Seattle, WA, USA

e-mail: cabral@hydrologyfutures.com

R. Coats

Hydroikos Ltd., Berkeley, CA, USA

R. Coats $\cdot$ J. Reuter $\cdot$ G. Sahoo $\cdot$ G. Schladow

Tahoe Environmental Research Center, University of California, Davis, CA, USA

S. B. Roy $\cdot$ L. Chen

Tetra Tech, Inc., R\&D, Lafayette, CA, USA

J. Reuter

Department of Environmental Science \& Policy, University of California, Davis, CA, USA

J. Riverson

Tetra Tech, Inc., Fairfax, VA, USA

G. Sahoo $\cdot$ G. Schladow

Department of Civil \& Environmental Engineering, University of California, Davis, CA, USA

B. Wolfe

Northwest Hydraulic Consultants, South Lake Tahoe, CA, USA 

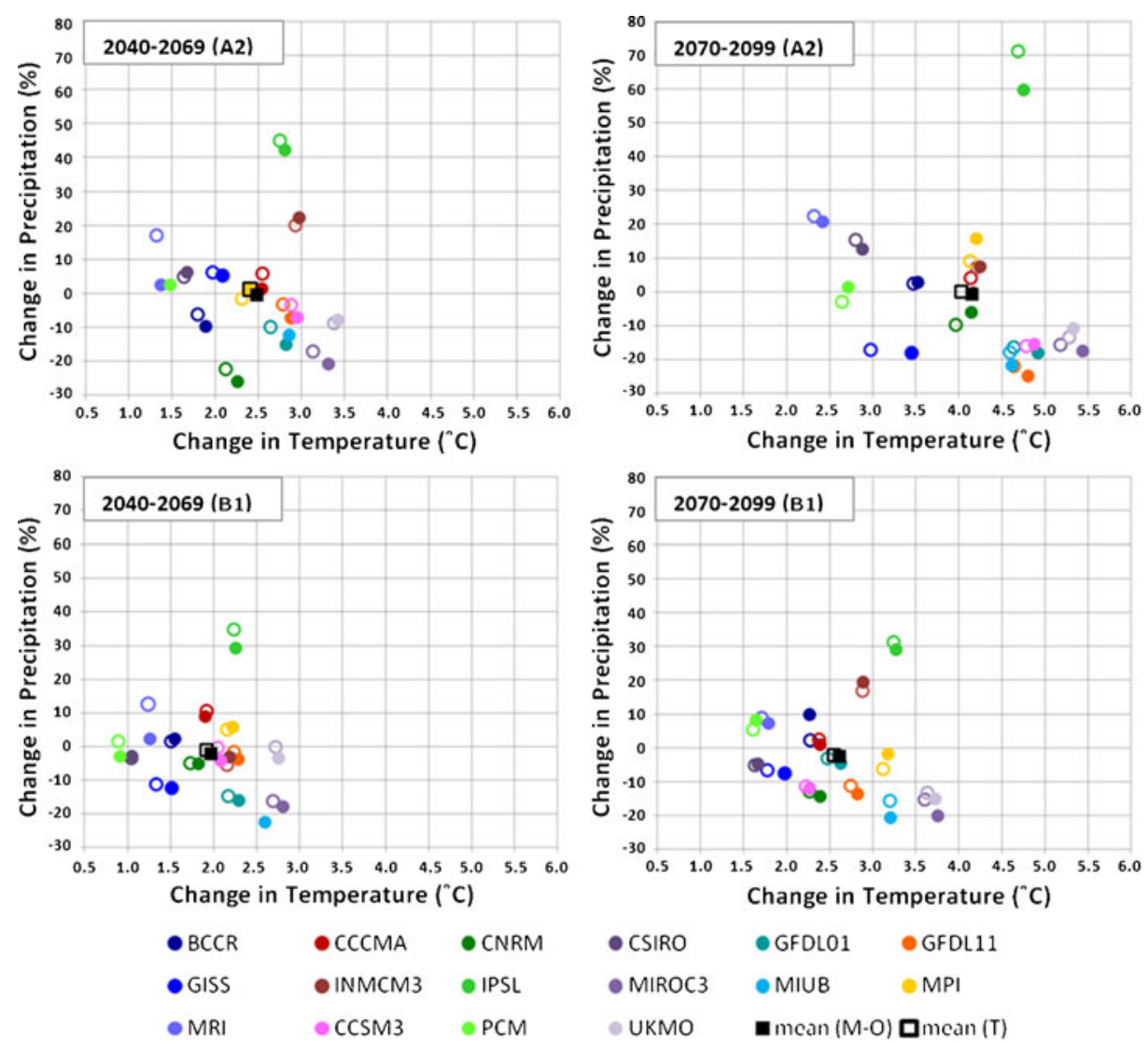

Fig. 2 Change in mean annual temperature and precipitation for the mid century period (2040-2066) and end of century period (2070-2099) projected by 16 GCMs and two greenhouse emissions scenarios, statistically downscaled to the location of Mono Lake (filled circles) and Lake Tahoe (open circles). Model means are represented by squares for Mono Lake (filled squares) and Lake Tahoe (open squares). For any given model, projections for the two lakes differ mildly, with a tendency for slightly greater warming and slightly smaller increases or greater declines in precipitation for Mono Lake relative to Lake Tahoe. The data plotted are from Maurer et al. (2007) 